Published in final edited form as:

Adv Drug Deliv Rev. 2009 June 21; 61(6): 457-466. doi:10.1016/j.addr.2009.03.010.

\title{
Effects of nanomaterial physicochemical properties on in vivo toxicity
}

\author{
Kristin L. Aillona,b, Yumei Xie ${ }^{a}$, Nashwa El-Gendy ${ }^{a, b}$, Cory J. Berkland ${ }^{a, b}$, and M. Laird \\ Forrest $^{\mathrm{a}}{ }^{*}$ \\ aDepartment of Pharmaceutical Chemistry, University of Kansas, Lawrence, KS, 66047 USA \\ ${ }^{b}$ Department of Chemical and Petroleum Engineering, University of Kansas, Lawrence, KS, 66047, \\ USA
}

\begin{abstract}
It is well recognized that physical and chemical properties of materials can alter dramatically at nanoscopic scale, and the growing use of nanotechnologies requires careful assessment of unexpected toxicities and biological interactions. However, most in vivo toxicity concerns focus primarily on pulmonary, oral, and dermal exposure to ultrafine particles. As nanomaterials expand as therapeutics and as diagnostic tools, parenteral administration of engineered nanomaterials should also be recognized as a critical aspect for toxicity consideration. Due to the complex nature of nanomaterials, conflicting studies have led to different views of their safety. Here, the physicochemical properties of four representative nanomaterials (dendrimers, carbon nanotubes, quantum dots, and gold nanoparticles) as it relates to their toxicity after systemic exposure is discussed.
\end{abstract}

\section{Keywords}

nanomaterial; toxicity; in vivo; dendrimer; carbon nanotube; quantum dot; gold nanoparticle; analysis

\section{Introduction}

Research involving the use of different types and designs of nanomaterials continues to evolve with the growth of nanotechnology for in vivo applications in such fields as drug delivery, medical imaging, diagnostics, and engineering technology [1-4]. Currently, several therapeutics are approved for use or are in clinical trials and it is expected that nanotechnology will be utilized in many more commercial products in the near future $[4,5]$.

The majority of nanotoxicity studies have focused on health effects of exposure to ultrafine (unintentionally produced) particles by inhalation, contact through skin, or ingestion [1,6-9]. These studies primarily focus on local effects (e.g. lung toxicity after particle inhalation). With a multitude of opportunities for nanomaterial use in pharmaceutical and medical applications, a thorough understanding of associated systemic toxicity is critical. Characterization of in vivo toxicity has been a daunting task as nanomaterials are quite complex and conflicting

(C) 2009 Elsevier B.V. All rights reserved

*Corresponding author. 2095 Constant Ave., Lawrence, KS, 66047 USA. Tel.: +1 785864 4388; fax: + 17858645736. mforrest@ ku.edu (M.L. Forrest)..

Publisher's Disclaimer: This is a PDF file of an unedited manuscript that has been accepted for publication. As a service to our customers we are providing this early version of the manuscript. The manuscript will undergo copyediting, typesetting, and review of the resulting proof before it is published in its final citable form. Please note that during the production process errors may be discovered which could affect the content, and all legal disclaimers that apply to the journal pertain. 
studies have led to different views of their use and safety. This makes it difficult to evaluate, generalize, and predict important aspects of toxicity [10]. Presented in this review are current studies evaluating the systemic toxicity of four representative nanomaterials (dendrimers, carbon nanotubes, quantum dots, and gold nanoparticles) as it relates to nanomaterial properties and design.

\subsection{Mechanisms of nanomaterial toxicity}

Nanomaterial toxicity can occur through several different mechanisms in the body. A summary of the major forms of in vivo nanomaterial toxicity is displayed in Fig. 1. As summarized by Lanone et al., the main molecular mechanism of in vivo nanotoxicity is the induction of oxidative stress by free radical formation [3]. In excess, free radicals cause damage to biological components through oxidation of lipids, proteins, and DNA. Oxidative stress may have a role in the induction or the enhancement of inflammation through upregulation of redox sensitive transcription factors (e.g. NF- $\mathrm{KB}$ ), activator protein-1, and kinases involved in inflammation $[3,11,12]$. Free radicals can originate from several sources including phagocytic cell response to foreign material, insufficient amounts of anti-oxidants, presence of transition metals, environmental factors, and, as focused in this review, physicochemical properties of some nanomaterials [3]. Slow clearance and tissue accumulation (storage) of potential free radical producing nanomaterials as well as prevalence of numerous phagocytic cells in the organs of the reticuloendothelial system (RES) makes organs such as the liver and spleen main targets of oxidative stress. Additionally, organs of high blood flow that are exposed to nanomaterials, such as the kidneys and lungs, can also be affected.

Intracellularly, nanomaterials may interact with cellular components, disrupt or alter cell function, or create reactive oxygen species (ROS). Interactions of nanomaterials with the mitochondria and cell nucleus are being considered as main sources of toxicity. As reviewed by Unfried et al., nanomaterials such as silver-coated gold nanoparticles, fullerenes, block copolymer micelles, and carbon nanotubes may be capable of localizing to mitochondria and inducing apoptosis and ROS formation and that nanomaterial-induced nuclear DNA damage, cell-cycle arrest, mutagenesis, and apoptosis is a possible source of toxicity [13]. Although still under debate, nanomaterials may be involved in the upregulation of NADPH oxidase and xanthine oxidase, which are free radical sources in macrophages and neutrophils [3].

Other mechanisms of toxicity from nanomaterials should be considered since nanomaterials immediately interact with their surrounding environment. When introduced or absorbed into the systemic circulation, interaction with blood components can lead to hemolysis and thrombosis. Additionally, nanomaterial interactions with the immune system have been known to increase immunotoxicity as reviewed by Dobrovolskaia et al. [5]. In the liver, further metabolic modification of nanomaterials, e.g. by cytochrome P450, may result in hepatotoxicity by reactive intermediates [3].

\subsection{Nanomaterial design considerations}

Nanomaterials have unique properties and characteristics relative to bulk materials (e.g. high surface area to volume ratio) that may endow them with unique mechanisms of toxicity from xenobiotics. In particular, toxicity has been thought to originate from nanomaterial size and surface area, composition, and shape as reviewed by Lanone et al. [3].

Size plays a role in how the body responds to, distributes and eliminates materials [10,14]. Particle size can also affect the mode of endocytosis, cellular uptake, and the efficiency of particle processing in the endocytic pathway $[3,15]$. In vitro studies of non-phagocytic cellular uptake of latex spheres have demonstrated slower uptake and processing of large spheres $(>200$ $\mathrm{nm})$ relative to small ones $(50$ and $100 \mathrm{~nm})$ [15]. More importantly, decreasing size also leads 
to an exponential increase in surface area relative to volume, thus making the nanomaterial surface more reactive on itself (aggregation) and to its surrounding environment (biological components). Increased uptake into certain tissues may lead to accumulation, where they may interfere with critical biological functions [3,7].

Chemical composition at the surface of nanomaterials will largely define their chemical interactions since the surface is in direct contact with the body whereas the limited bulk volume is hidden [10]. Therefore, nanomaterials behave quite differently than bulk materials. Many nanomaterials are functionalized on the surface to increase blood circulation, make them more biocompatible, and for targeted therapy. While functionalization has shown promise in many applications, functional groups added to the surface can potentially interact with biological components, alter biological function, and allow passage of nanomaterials that would not normally be taken up by certain cells.

Degradability of the material is an important component of acute and long-term toxicity. Nondegradable nanomaterials can accumulate in organs and also intracellularly where they can cause detrimental effects to the cell, similar to that of lysosomal storage diseases [2]. In contrast, biodegradable nanomaterials can lead to unpredicted toxicity due to unexpected toxic degradation products [6]. Nanomaterials may contain transition metals (e.g. quantum dots) or other compounds with known toxicity that are "masked" for instance by functionalization. Degradation of this material may release toxins to the biological milieu, leading to free radical formation and resulting in cellular damage $[3,6]$.

As elicudated from the effects of asbestos fibers in the lungs and studies of intratracheal instillation, nanomaterials may be capable of evading macrophage uptake and RES clearance [8,16-18]. Although known that slow dissolution of particles can overwhelm macrophagemediated clearance resulting in particle persistence, the shape of nanomaterial may also play a role in effective clearance. Recent investigations by Champion et al. have described macrophage interaction with different shaped nanomaterials [19]. They discovered that failure to create the required actin-driven movement of the macrophage membrane results in the macrophage spreading onto the material rather than internalization. Therefore, complete phagocytosis is based on the point of macrophage contact, with less internalization with rodlike materials relative to spherical materials. Though this study was specific to alveolar macrophages, similar results may be applicable to other tissues.

\section{In vivo toxicity of nanomaterials}

The uniqueness of each type of nanomaterial being explored for medical applications makes generalization of nanomaterial toxicity rather complicated. To elucidate causes of toxicity, current research evaluating the distribution and toxicity of nanomaterials usually focuses on one aspect of the material properties at a time (e.g. effect of altering surface charge). Current research on the effects of nanomaterial properties of selected types of nanomaterials is discussed in this section with the primary nanomaterial toxicity concerns summarized in Table 1.

\subsection{Dendrimers}

Traditional polymer drug delivery systems utilize linear, random-coil polymers such as polyethylene glycol, $N$-(2-hydroxypropyl) methacrylaminde copolymers, poly

(ethyleneimine), poly(lactic acid), poly(glycolic acid) and their copolymers, dextrin ( $\alpha-1,4$ polyglucose), hyaluronic acid, chitosans, poly(glutamic acid), and poly(aspartamides) [20, 21]. The major obstacle using these polymeric materials in biomedical and pharmaceutical applications is the heterogenic nature of these polymers. The conventional polymerization methods for these linear polymers usually result in polymers with different chain lengths 
(molecular weights), different chemical structures, and polydispersity. Therefore, these polymers are not reproducible batch to batch, which makes it difficult to define their in vivo behaviors (e.g. biodistribution, pharmacokinetics, stability, toxicity) using validated techniques. Low drug carrying capacity of these linear polymers and variable drug release kinetics in vivo all contribute to the lack of improved therapeutic index of the loaded drug.

Dendrimers, also called arboroles or cascade polymers, are well-defined, highly branched macromolecules with precisely controlled chemical structure and low polydispersity (Fig. 2). Dendrimers are synthesized in a stepwise process either by a "divergent method" or "convergent method". In the divergent method, synthesis starts with a multifunctional core followed by repeated addition of monomers and increase in molecular weight with exponential increase in surface termini. By contrast, the convergent method starts from the dendrimer surface and proceeds inward to a multivalent core where the dendrimer segments are joined together. Dendrimer branching offers advantages such as nano-size spherical structures (for high generations), low viscosity compared to equivalent molecular weight linear polymers, narrow polydispersity, and high density of surface functionalities [22]. Over the past three decades, dendrimers such as polyamidoamine (PAMAM, i.e. Starburst ${ }^{\mathrm{TM}}$ ) $[23,24]$, poly (propylenemine) (PPI) [25,26], triazine [27,28], and poly-L-lysine (PLL) [29-31] have been used widely as vehicles for drug or gene delivery. However, the in vivo toxicity of dendrimers has not been systematically investigated [32]. This review mainly focuses on PAMAM dendrimers since they are one of the most studied dendrimers.

Depending on the dendrimer type and generation, they carry a positive, neutral, or negative charge on the surface. Once introduced into the systemic circulation, positively charged dendrimers and cationic macromolecules have been found to interact with blood components, destabilize cell membranes, and cause cell lysis [33-35]. Roberts et al. studied the toxicity of cationic PAMAM Starburst ${ }^{\circledR}$ in mice [24]. Cationic dendrimers of generation 3 (G3, MW 5147, diameter $31 \AA$, 24 amine termini), generation 5 (G5, MW 21563, diameter $53 \AA$, 96 amine termini), and generation 7 (G7, MW 87227, diameter $80 \AA$, 768 amine termini) were given i.p. with doses ranging from 0.026 to $45 \mathrm{mg} / \mathrm{kg}$ either as a single dose or once a week for 10 weeks. The in vivo toxicity was evaluated by behavioral abnormalities $2 \mathrm{~h}$ post injection and by body weight changes up to 6 months. No significant behavioral abnormality or weight loss was observed through the study. However, one out of five mice died at about $24 \mathrm{~h}$ after dendrimer injection in the G7 group with highest dose of $45 \mathrm{mg} / \mathrm{kg}$. These studies suggest that low generation cationic dendrimers $(G<7)$ even at high doses do not cause adverse effects. However, Heiden et al. found cationic PAMAM dendrimers (G4, amine termini) were toxic to zebrafish embryos, and the toxicity was dose and exposure duration dependent [36]. A mortality of $100 \%$ was observed by $24 \mathrm{~h}$ post fertilization when the dendrimer concentration exceeded $20 \mu \mathrm{M}$. In the same study by contrast, anionic PAMAM dendrimers (G3.5, carboxylic acid termini) were not toxic and showed no signs of attenuating embryo development. G4 dendrimers conjugated to Arg-Gly-Asp (RGD) were much less toxic compared to unconjugated G4 dendrimers. Malik et al. also found that $95 \mathrm{mg} / \mathrm{kg}$ daily doses of anionic PAMAM dendrimers (G3.5, carboxylic acid termini) administered i.p. led to no mortalities and no weight change in B16F10 tumor bearing mice [37]. Overall, these studies indicated that dendrimer toxicity is dose and generation dependent with higher dose and higher generation dendrimers leading to more toxicity in vivo. The toxicity profiles also depend greatly on the surface charge of the dendrimers, that is, anionic dendrimers are less toxic compared to cationic dendrimers.

Hematological toxicity is one of the most important concerns for dendrimers given intravenously. Cationic dendrimers such as $-\mathrm{NH}_{2}$ PAMAM have shown concentration and generation dependent hemolysis and induced morphology changes in red blood cells after $1 \mathrm{~h}$ incubation at a low concentration of $10 \mu \mathrm{g} / \mathrm{mL}$; whereas, anionic dendrimers were not hemolytic at concentrations up to $2 \mathrm{mg} / \mathrm{mL}$ [23]. Agashe et al. examined the hematological 
toxicities of generation 5 PPI dendrimer (PPI-5.0G), t-BOC-protected glycine-coated dendrimer (DBG), t-BOC-protected phenylalanine-coated dendrimer (DBPA), mannosecoated dendrimer (M-PPI) and lactose-coated dendrimer (L-PPI) [25]. Dendrimers were administered i.v. into male albino rats (equivalent to $1-4 \mathrm{mg}$ of each polymer), and after 7 days, blood samples were collected and analyzed to determine hematological parameters such as white blood corpuscles (WBCs), red blood cells (RBCs), hemoglobin (Hb), haematocrit (HCT) and mean corpuscular hemoglobin $(\mathrm{MCH})$. Compared to the control group, there were significantly higher WBC counts and lower RBC, HCT, Hb, and MCH values for the PPI-5.0G group, probably due to the polycationic nature of the dendrimers. Surface modified dendrimers (DBG, DBPA, M-PPI and L-PPI) showed no difference in terms of hematological parameters compared to the control group.

Immunogenicity is the ability of antigens to induce humoral or cell-mediated immune responses. Immunogenicity should be avoided if the immune system is not the intended target of the dendrimer drug delivery system. The immunogenicity of PAMAM (G3, G5 and G7) dendrimers at a dose of $5 \times 10^{-5} \mathrm{mmol}$ was studied in rabbits, and no evidence of immunogenicity was found 10 days after i.p. injection by the immunoprecipitation assay or the Ouchterlony double diffusion assay [24]. Five PPI-based dendrimers (PPI-5.0G, DBG, DBPA, M-PPI and L-PPI) were injected intramuscularly into Balb/C mice at dose levels of 1-4 mg of dendrimer [25]. Blood samples were collected after 21 days and antibody (IgG) titre was tested by ELISA. The antibody (IgG) level in blood was non-detectable, which indicated no sign of humoral immune response triggered by the dendrimers. However, these studies only tested short-term immunogenicity. The in vivo studies of cell-medicated immune response and complement activation have not been reported though a G5 PAMAM dendrimer has been seen to induce strong complement activation in vitro [38].

Nephrotoxicity and hepatotoxicity have been reported consistent with biodistribution studies that revealed high kidney and liver accumulation for G3 PAMAM dendrimers (i.p.) [24], G3 and G4 PAMAM dendrimers (i.v. or i.p.) [23], biotinylated-PAMAM dendrimers (G0-4) (i.v.) [39], and PEG-polyester dendritic hybrids (i.v.) [40]. Roberts et al. noticed liver cell vacuolization of the cytoplasm in a 6-month toxicity study group after administration of G7 PAMAM dendrimers by i.p. route once a week for 10 weeks [24]. A third generation melamine dendrimer (MW 8067, 24 amine termini) was evaluated for in vivo acute (single dose, $48 \mathrm{~h}$ ) and subchronic (three i.p. injections every 3 weeks over 6 weeks) toxicities [41]. The acute study indicated the lethal dose was $160 \mathrm{mg} / \mathrm{kg}$, giving rise to $100 \%$ mortality $6-12 \mathrm{~h}$ post injection. In both acute and subchronic studies, there was no significant renal damage in all dose ranges as determined by blood urea nitrogen levels. Hepatic function was normal at up to $10 \mathrm{mg} / \mathrm{kg}$ dendrimer as evaluated by changes in serum alanine transaminase (ALT) activity. However, a significant increase in ALT activity noticed for both acute and subchronic groups at the $40 \mathrm{mg} / \mathrm{kg}$ dose level, and the histopathological investigation showed extensive liver necrosis.

Dendrimer modification with chemically inert polyethylene glycol (PEG) or fatty acids is one of the most attractive ways to reduce dendrimer toxicities in vitro [35,42-44]. PEG-polyester dendritic hybrids (3-arm PEG star and G2 polyester dendrons, MW 23,500 Da) were injected into mice as an i.v. bolus dose of $1.3 \mathrm{~g} / \mathrm{kg}$ [40]. Mice survived after $24 \mathrm{~h}$, and no changes of organ pathology were observed in the liver, lungs, heart, kidney, or intestine. PEGylated melamine dendrimer (G3, PEG 2000 termini) was administered at doses of $2.56 \mathrm{~g} / \mathrm{kg}$ i.p. and $1.28 \mathrm{~g} / \mathrm{kg}$ i.v. into $\mathrm{C} 3 \mathrm{H}$ mice, and all mice survived after $24 \mathrm{~h}$ and $48 \mathrm{~h}$ after i.p. and i.v. administration, respectively, with no liver or kidney toxicity noted [45].

The non-biodegradability of PAMAM/PPI-type dendrimers is of major concern for their medical use. Biodistribution studies of magnetic resonance imaging (MRI) contrast agents 
based on PAMAM/PPI dendrimer-gadolinium (Gd) chelates have been reported. Lower generations of PAMAM-Gd (diameter $<10 \mathrm{~nm}$ ) were excreted via kidney and the renal elimination rate decreased with increasing dendrimer size. Minimal renal excretion and high RES uptake were observed when PAMAM-Gd size exceeded $10 \mathrm{~nm}$ [46-49]. It was also noticed that only less than $15 \%$ of the injected PAMAM-Gd agents (PAMAM G4, G5, and G6) were excreted within 2 days [49]. Dendrimer core structure also influences the biodistribution of the dendrimer MRI agents. Compared to the PAMAM-Gd, a less hydrophilic PPI diaminobutane core contributes to the dramatic increase in liver accumulation [50]. Although PEGylation and other surface modification schemes may reduce the potential of harmful biological interactions, the dendrimer core material must be biodegradable or readily eliminated by the renal or hepatic system. Otherwise, the long-term toxicity is difficult to predict. The amide core of PAMAM and PPI type dendrimers cannot undergo hydrolysis or enzymatic degradation. Newer dendrimers where the core is structured from amino acids, oligonucleotides, or polyesters may overcome these toxicity concerns [51-56].

In conclusion, in vivo dendrimer toxicity profiles are closely related to the chemical structure of dendrimer; size and generation; exposure duration; biodistribution; and the rate, location, and mechanism of metabolism. Toxicity of dendrimers is influenced by the nature of the terminal groups. Full generation PAMAM dendrimers with cationic amine terminal groups are more toxic than half-generation dendrimers with anionic carboxylic acid terminal groups. High generations and high doses of cationic dendrimers usually lead to greater in vivo toxicity. Surface modification with PEG or fatty acids improves dendrimer biocompatibility. In order to design a more safe and non-toxic dendrimer drug delivery system, larger and more systematic toxicity studies are required.

\subsection{Carbon nanotubes}

Carbon nanotubes (CNT) are a class of fullerenes consisting of a sheet of graphene arranged into small cylindrical structures (Fig. 2). There at two types of CNT: single-walled (SWCNT) and multi-walled (MWCNT). SWCNT are a single tube of graphene with a diameter ranging from 0.4-3.0 nm and a length up to $1 \mu \mathrm{m}$ [57,58]. MWCNT are multiple layers of tubes stacking within each other with an overall diameter of 1.4-100 nm and can be up to several microns long [58]. In the last few years, both SWCNT and MWCNT have been utilized as nanocarriers for parenteral drug and gene delivery and recently as targeted cancer treatments [3,59]. The safety of CNT is still in debate due to the lack of systematic and complete toxicity evaluation [60]. Recently, studies have indicated that CNT responses are similar to the carcinogenic responses of asbestos fibers when injected into the peritoneal cavity [61,62]. Due to the high aspect ratio of CNT (>100), it is expected that CNT would behave as biopersistent fibers in vivo. Studies have implicated size (aggregation), CNT length, and manufacturing impurities as sources for potential toxicity in vivo and will be discussed herein.

The size of aggregated CNT is thought to be a primary concern for toxicity. Pristine (nonfunctionalized) CNT are inherently hydrophobic; therefore, aggregation is expected and observed in vivo. For injection, pristine CNT are suspended in biocompatible surfactants such as Tween 80 or Pluronic F108 [63,64]. Several studies have been conducted on the in vivo distribution of i.v. injected pristine SWCNT. Primarily, accumulation of CNT was determined to be in the liver, but also in the spleen and lungs. No acute toxicity was observed in any tissues up to $24 \mathrm{~h} \mathrm{[63-65].} \mathrm{Accumulation} \mathrm{in} \mathrm{the} \mathrm{liver} \mathrm{was} \mathrm{suggested} \mathrm{to} \mathrm{be} \mathrm{due} \mathrm{to} \mathrm{rapid} \mathrm{surfactant}$ displacement followed by opsonization of serum proteins [63]. Yang et al. followed up distribution studies by looking at serum biomarkers of damage. Additionally, they looked at markers for oxidative stress (glutathione and malondialdehyde) in liver and lung samples post dose [64]. Elevated levels of lactose dehydrogenase and alanine aminotransferase were concluded to be due to hepatic injury from accumulation in the liver. They also found an 
increase in malondialdehyde and a decrease in glutathione in liver and lung samples (at 1.0 $\mathrm{mg} / \mathrm{mouse}$ ), which was indicative of increased levels of oxidative stress. Although no acute toxicity was determined histologically up to 90 days post dose, biomarkers indicating hepatic injury due to oxidative stress should be further investigated [64]. Studies conducted longer than 90 days may exhibit more toxicity damage over time, similar to onset of damage from asbestos fibers in lungs, which could take years. ROS formation and cytotoxic effects induced by aggregates and accumulation have been observed in other studies of CNT [66,67]. A study by Faczek et al. compared pristine SWCNT and MWCNT compatibility in muscle implants [68]. They determined that both types of CNT formed aggregates when implanted in rat skeletal muscle; however, MWCNT produced larger aggregates that continued to get larger over the 90-day study. SWCNT agglomerates remained the same size throughout the study and underwent phagocytosis with subsequent drainage to the lymph nodes. MWCNT, on the other hand, did not translocate to the lymph and remained accumulated in the muscle tissue [68]. Improper phagocytosis may be due to the large diameter of the MWCNT based on aggregation. Reduction of CNT accumulation and aggregation is achieved by functionalization [69-71]. Rapid distribution and renal clearance from almost all tissues is observed 1-3 days after injection of functionalized CNT, whereas pristine CNT were determined at high levels in RES tissues up to 1 month after injection [65]. Even though functionalization of carbon nanotubes is more promising for medical applications, current toxicity studies focus primarily on environmental health concerns of pristine CNT. No comprehensive examination of functionalized CNT degradation-induced toxicity has been reported, but these are important questions as functionalized CNT have more promise as therapeutics and diagnostic tools.

Along with CNT aggregation as a function of improper macrophage uptake, the length of CNT has been implicated as a source of improper macrophage translocation. Poland et al. studied the effect of length on CNT toxicity by injecting MWCNT i.p. and observing carcinogenic mechanisms in the abdominal cavity and on the diaphragm [61]. The longer length ( $\geq 20 \mu \mathrm{m}$ ) CNT resulted in an inflammatory response within $24 \mathrm{~h}$ with consequent granuloma 7 days after injection. These longer lengths may cause carcinogenic effects such as mesotheliomas, if longer studies were conducted. In the same study, shorter lengths of i.p injected MWCNT were effectively taken up by macrophages with efficient phagocytosis. In terms of CNT for therapeutics, it can be deduced that SWCNT may be more favorable than MWCNT from a toxicology standpoint due to smaller size and length resulting in less aggregation and better uptake by macrophages. Hirano et al. further suggested that MWCNTs are recognized and interact with macrophage receptors on the plasma membrane and can rupture the membrane causing cytotoxicity and damage to the macrophage [72].

Methods of CNT fabrication and purification have been shown to increase toxic effects of CNT. Arc-discharge, laser ablation, chemical vapor deposition, and high-pressure carbon monoxide synthesis are methods commonly used to fabricate CNT $[69,73]$. These methods are often performed in the presence of metal catalysts with CNT growth occurring on solid supports. Impurities such as residual metal or supports and amorphous carbon in the final formulation have been thought to induce oxidative stress. On the other hand, extensive purification and treatment will also cause degradation of the nanotubes [73]. Therefore, a fine balance between synthetic methods and purification must be achieved to fabricate highly purified CNT for injection.

Low clearance and accumulation of CNT in vivo warrants studies to determine chronic exposure toxicity. Radiolabeled isotopes are commonly used to evaluate the in vivo performance of CNT [70,71]. However, due to isotopic decay and degradation of the label from the CNT, radiolabeling suffers from short study timeframes. Recently, Liu et al. and Cherukuri et al. have used Raman spectroscopy and near-infrared fluorescence, respectively, for intrinsic detection of CNT in tissue homogenates, urine, and feces samples [63,69]. Yang et al. 
determined that pristine SWCNT remained stable up to 28 days in lungs, liver, and spleen by TEM visualization in mice that were injected i.v. with a high dose of CNT [64]. Therefore, estimation and evaluation of chronic exposure toxicity may be possible based on evaluation of CNT intrinsic properties.

In conclusion, toxicity concerns of general CNT use in vivo have stemmed from observed toxicity after delivery to the lungs. Current studies have shown that once in the bloodstream, intrinsic properties, propensity to aggregate, and slow clearance can lead to oxidative stress especially in the liver, lungs and spleen, ultimately resulting in inflammation. More importantly, the length of CNT has been shown to result in inefficient phagocytosis and damage to macrophages. Due to less aggregation and shorter lengths, SWCNT are better suited for in vivo applications over MWCNT. Functionalization of SWCNT further reduces aggregation; however, more thorough research on functionalized CNT toxicity will need to be conducted. Moreover, methodically conducted experiments that mimic chronic exposure to CNT will be more productive in the determination of CNT nanotoxicity.

\subsection{Quantum dots}

Quantum dots (QDs) are fluorescent semiconductor nanocrystals $(\sim 2-100 \mathrm{~nm})$ with unique optical and electrical properties [74,75]. QDs possess high brightness due to their extinction coefficient and quantum yield, broad absorption characteristics, narrow line width in emission spectra, continuous and tunable emission maxima due to quantum size effects, and a longer fluorescence lifetime with negligible photobleaching over minutes to hours [76-79]. These properties make QDs advantageous in biotechnology and medical applications as optimal fluorophores for in vivo biomedical imaging and for targeting specific cells (e.g., labeling neoplastic cells, peroxisomes, DNA, and cell membrane receptors) after conjugation with specific bioactive moieties [80-85]. These applications are predicted to grow because of their numerous advantages over alternative biological labeling moieties (e.g. fluorescent dyes and radioisotopes).

QDs have a metalloid crystalline core (e.g. CdSe) and a shell (e.g. ZnS) that shields the core (Fig. 2) [86]. The core consists of a variety of metal complexes such as semiconductors, noble metals, and magnetic transition metals $[87,88]$. The shell, formed on the metalloid core during synthesis in organic solvents, makes QDs hydrophobic, and hence limits their use in biological applications. To make QDs biocompatible, secondary coatings are added that improve water solubility, QD core durability, and suspension characteristics. These organic coatings can be used towards targeting biological components for diagnostic or therapeutic purposes [89].

The safety of metals and their use in vivo is an ongoing topic of debate. Divalent cations are known to be toxic, even at low concentrations in the body. Due to reabsorption and accumulation in the kidneys, the main problem with heavy metals is nephrotoxicity [90]. For example, gadolinium-based contrast agents for clinical MRI analysis have been reported to be associated with acute renal failure [91]. Some researchers have considered QDs to be inert structures where the metallic core is safely passivated, while others have dismissed the use of QDs in vivo because of potential toxicity. Cadmium and selenium, two of the most used metals in QD cores, are known to cause acute and chronic toxicities in vertebrates and are of significant health and environmental concern [92]. Cadmium has a biological half-life of 15-20 years in humans, accumulates in tissues, and can cross the blood-brain barrier and the placenta. In the case of QDs, release of $\mathrm{Cd}^{2+}$ from the core and generation of ROS and oxidative stress appears to be the mechanism of in vivo toxicity $[93,94]$. Although researchers agree on the toxicity of $\mathrm{Cd}^{2+}$, conflicts remain on the use of QDs in vivo. Studies have suggested that the shell (most commonly $\mathrm{ZnS}$ ) along with secondary coatings prevent $\mathrm{Cd}^{2+}$ leakage from the core [95]. Others suggest that $\mathrm{Cd}^{2+}$ can leak from the core with QD complex instability. Arguments of QD safety can be somewhat confusing because of the variety of QDs being synthesized and considered. 
Studies concluding that QDs are toxic indicate that toxicity may originate from QD stability, size, surface charge, and type of surface coating.

Possibly the most important aspect of QD toxicity is the stability of the core/shell/coating complex. Stable complexes should protect the body from core metal toxicity. Several studies suggested that under oxidative and photolytic conditions, QD are labile and subject to degradation, thus exposing the potentially toxic shell material, intact core metalloid complex, and core metal components (e.g. $\mathrm{Cd}, \mathrm{Se}$ ) [75]. It has been reported that $\mathrm{Cd}^{2+}$ released under oxidative attack can bind to the sulfhydryl groups of critical mitochondria proteins leading to mitochondria dysfunction and ultimately cell poisoning [92]. Addition of the secondary surface coating renders QDs biocompatible and can help protect against degradation of QDs, but the method of functionalization (e.g. electrostatic, adsorption, multivalent chelation, or covalent bonding) and the coating composition are important when considering QD durability, stability, and in vivo reactivity [75]. Interestingly, a recent communication by Mancinci et al. suggests an oxidative mechanism wherein hypochlorous acid and hydrogen peroxide, both produced by phagocytic cells, may diffuse across polymeric secondary coatings and cause QD lattice defects and solubility of the core [96]. Therefore, there may be in vivo oxidative mechanisms of QD degradation regardless of the presence of stable secondary coatings.

Some studies have suggested that QD size is the source of toxicity regardless of the presence or absence of secondary coating. Shiohara et al. studied the cytotoxicity of $\mathrm{CdSe} / \mathrm{ZnS}$ coated with mercaptoundecanoic acid (MUA), resulting in a carboxyl-QD, in three different cell lines. They determined that increased cell death correlated with a decrease in QD size even at low concentrations [78]. These results were consistent with studies by Zhang et al. supporting increased cytotoxicity with small sized QDs in rat hepatocytes [97].

Since a secondary coating is almost always used for in vivo applications, many studies have focused on what roles coatings play on QD stability relative to nanoparticle toxicity [95]. To assess the importance of surface charge, many groups have studied the toxicity of cationic (amine) and anionic (carboxyl) secondary coatings on QDs. Geys et al. conducted an acute in vivo toxicity study on amine- and carboxyl-coated commercially available CdSe/ZnS QDs. Low doses of 1.44 pmol or 14.4 pmol of both types did not elicit acute adverse effects. However, at high doses the QDs caused pulmonary vascular thrombosis, with carboxyl-QDs being more potent in inducing this effect than amine-QDs. Because fibrin fibers were present in the thrombi and because pretreatment with heparin abolished the thrombotic effects, they speculated that negatively charged QDs activated the coagulation cascade via contact activation [98]. Hoshino et al. coated CdSe/ZnS with mercaptoundecanoic acid (MUA) (QD-COOH), cysteamine (QD$\mathrm{NH}_{2}$ ), thioglycerol (QD-OH), QD-OH/COOH and QD-NH$/ 2 / O H$ to assess the effects of surface charge on the cytotoxicity of hepatocytes. They found that the highly negative charge QD$\mathrm{COOH}$ induced DNA damage after $2 \mathrm{~h}$ while the other types have no significant cellular damage [99]. They suggest that after endocytosis, the acidic nature of the endosome creates QD-COOH instability in the cell where QDs can easily aggregate. However, only amine-QDs were stable in acidic conditions ( $100 \mathrm{nM}$ QD incubated in glycine buffer $(\mathrm{pH}=3.0)$ for $30 \mathrm{~min}$ at room temperature) [100]. Overall, a balance of surface charge should be considered in evaluating potential stability and toxicity issues.

The type of secondary surface coating may affect the toxicity of the QD complex. Polyethylene glycol (PEG), a common pharmaceutical excipient, is used extensively in commercially available QDs. Ballou et al. prepared QDs coated with amphiphilic polyacrylic acid and simultaneously conjugated to different molecular weights of PEG (750 and 5000). By monitoring QDs in mice with fluorescent imaging, they found that significant liver uptake was visible even at 1 min using (750)-PEG-QD, but completely cleared away after $1 \mathrm{~h}$, while (5000)PEG-QD was absorbed by liver in 1-3 h post-injection. They determined no significant liver 
toxicity; however, they found differences in accumulation and clearance [101]. A longer study (28 days) was carried out by Yang et al. on a commercially available QD, (5000)-PEG-ZnS/ CdTe (QD705, about $13 \mathrm{~nm}$ ). After a single i.v. injection in mice, they demonstrated that the liver and spleen were the main accumulative organs. QDs were not detected in either urine or feces, which would suggest accumulation of QDs with high molecular weight PEG [89]. When PEG-QDs are injected subcutaneously, QDs clear from the site of injection and accumulate in the regional lymph nodes along with the liver, spleen, and kidney [102]. Therefore, the type of injection would need to be considered for QD accumulation and toxicity [75,103]. Albumin is another commonly used secondary coating for QD in vivo applications. Fisher et al. coated $\mathrm{CdSe} / \mathrm{ZnS}$ with MUA/ lysine to form QD-LM (about $25 \mathrm{~nm}$ ) or coated the QD-LM with bovine serum albumin (BSA) to form QD-LM-BSA (about $80 \mathrm{~nm}$ ). After i.v. injection in the rat, both QDs were mainly detected in the liver, although QDs were detected in the spleen, lung, kidney, and bone marrow. However, the QD-LMBSA liver uptake was greater (99\%) relative to the QD-LM uptake (40\%). This corresponded with a faster blood clearance of QD-LM-BSA. Neither type of QD was detected in the urine or feces up to 10 days, which would suggest accumulation in the liver, especially with BSA conjugation [104]. Overall, most studies have indicated that differences in coating material and size lead to changes in pharmacokinetics and can potentially cause toxicity.

In conclusion, the potential toxic effects of QDs have become a hot issue that must be further addressed before clinical applications would be possible. Most studies recommend that not all QDs are similar in their toxicity, and toxicity of differing QDs must be considered individually. The adverse effects of QD can be mitigated or eliminated by proper choices of coating materials and modification techniques that reduce QD instability.

\subsection{Gold nanoparticles}

Due to a straightforward synthesis, stability, and ease of incorporation of functional groups for targeting capabilities, gold nanomaterials have great application in gene and protein delivery, biological imaging, cancer treatments, and in implants (e.g. pacemakers and stents)

[105-107]. Additionally, gold has been used as anti-inflammatory and anti-rheumatic agents (Auranofin ${ }^{\circledR}$ and Tauredon ${ }^{\circledR}$ ) in the treatment of rheumatoid arthritis [107]. Many studies have suggested that gold nanomaterials are bioinert and can be used safely. This thought may be due to the established safety of bulk gold materials, but as the size decreases into the nanoscopic dimensions, gold will behave very differently than in bulk. Some research has found gold to be toxic in the body, where elemental gold can undergo oxidation or become soluble by cyanidation $[108,109]$. Studies have shown that gold is heavily taken up by the kidneys, causing nephrotoxicity, and can also initiate eryptosis (erythrocyte suicidal death) [110,111]. Studies have suggested that the size, surface charge, and shape are key factors related to potential toxicity of medicinal gold complexes.

Several studies have examined the effect of gold nanoparticle size on toxicity. Specifically, gold nanoclusters (illustrated in Fig. 2) of $1.4 \mathrm{~nm}$ have been shown to selectively and irreversibly bind to the major grooves of B-DNA and cause increased cytotoxicity compared to larger particles $(18 \mathrm{~nm})$. The lack of interaction of larger particles with DNA is suggested to be due to steric hindrance. While gold nanoclusters may be very effective cancer treatments, healthy cells would also be affected potentially causing toxicity $[112,113]$. Similarly, Pan et al. studied the size-dependent cytotoxicity of gold nanoparticles (water soluble and stabilized with triphenylphosphine derivatives) on several different cell lines. They discovered that nanoclusters of $1.4 \mathrm{~nm}$ exhibited increased cytotoxicity $\left(\mathrm{IC}_{50}=30\right.$ and $\left.46 \mu \mathrm{M}\right)$, whereas nanoclusters of $0.8,1.2$, and $1.8 \mathrm{~nm}$ where four to six-fold less toxic. Larger sizes ( $15 \mathrm{~nm}$ ) exhibited no cytotoxicity even at high concentrations $(6.3 \mathrm{mM})$ [114]. Moreover, Chithrani et al. examined the uptake of 14, 50, and $74 \mathrm{~nm}$ sized citric acid ligand stabilized gold 
nanoparticles into HeLa cells and determined that 50-nm spheres were more quickly taken up by endocytosis than both the smaller and larger sizes [115]. They further studied the rate of exocytosis of transferrin-coated gold nanoparticles and determined that the rate of exocytosis was size-dependent with more accumulation of larger gold nanoparticles in the cell [116]. When studying the effect of gold nanoparticle size after i.v. injection of colloidal gold in mice, smaller particles $(10-50 \mathrm{~nm}$ ) were found to disperse quickly to almost all tissues, mainly accumulating in the liver, lungs, spleen, and kidneys at $24 \mathrm{~h}$ post injection. Larger particles $(100-200 \mathrm{~nm})$ were found in the liver, lungs, spleen, and kidneys, but they were not as widely dispersed into other tissues as were the smaller particles. These studies concluded a sizedependent distribution and potential toxicity of smaller $(<50 \mathrm{~nm})$ gold nanoparticles [105, 117].

To condense and deliver pDNA successfully, synthetic gene transfection vectors generally must be cationic. Sandhu et al. determined that cationic gold nanoparticles were 8 -fold more efficient as a non-viral gene vector over the commonly used polymer polyethyleneimine [118]. Goodman et al. examined the effects of gold nanoparticle surface charge on cytotoxicity by studying cationic (amine) and anionic (carboxyl) gold nanoparticles on Cos-1 cells, red blood cells, and E. coli. It was concluded that cationic gold particles were moderately toxic and anionic particles were nontoxic, suggesting the initial electrostatic binding of the particles to the negatively charged cell membrane as a probable mechanism of toxicity and that electrostatic repulsion may limit anionic and neutral particle interaction with the cell surface [119]. So, cationic gold nanoparticles can be expected to exhibit more toxic effects relative to anionic particles. However, this would need to be performed in vivo for a better assessment of the effects of surface charge on biological interaction and gold nanoparticle toxicity.

Gold nanomaterials can be found in many different shapes, especially as spherical clusters and nanorods. Along with size, Chithrani et al. studied the effect of shape on the cellular uptake of gold nanoparticles. They concluded that both nanorods $(74 \times 14 \mathrm{~nm})$ and spherical particles (74 and $14 \mathrm{~nm}$ ) are taken up by cells; however, nanorod uptake is slower relative to spherical particles in HeLa cells [115]. Wang et al. further concluded that nanorods are more cytotoxic than spherical gold nanomaterials to human HeCaT keratinocytes [120]. Although both studies concluded differences between spherical particles and nanorods, both Chithrani et al. and Wang et al. suggested that the more important difference in cellular uptake rates and cytotoxicity was the use of different chemistries to stabilize the gold nanomaterials. During synthesis, cetyltrimethylammonium bromide (CTAB) is a commonly used cationic surfactant to stabilize gold nanorods. Although aggregation of gold nanorods has been shown intercellularly, nanospheres also show aggregation without causing cytotoxicity $[120,121]$. This led to future investigation into the toxicity of CTAB with several studies recognizing it as a main source of toxicity of gold nanorods [120-122]. CTAB surface reduction has been achieved by displacement of CTAB with PEG, citric acid ligands, and by coating gold nanoparticle surfaces with transferrin. Studies have concluded that these modified gold nanoparticles do not exhibit cytotoxic effects, although the amount of displaced CTAB is difficult to quantify with current analytical methods [115,120-123]. In vivo studies on the effects of CTAB and aggregation of gold nanomaterials will need to be evaluated, as well as more complete studies on the effects of gold nanoparticle shape on toxicity. Additionally, alternative means to stabilize gold nanorods need to be considered.

In conclusion, gold nanoparticles have numerous medical applications and traditionally have been thought of as bioinert since bulk gold has been deemed as such. However, more studies are suggesting potential toxicity concerns for gold nanoparticles due to their size, surface charge, and shape - the same unique properties that make them so appealing for medical applications. Unfortunately, most of the studies suggesting toxicity of gold nanoparticles come 
from in vitro experimentation. Thorough distribution and toxicity studies are critically needed to fully evaluate gold nanoparticles for in vivo use.

\section{Analysis of nanomaterial toxicity}

As current studies show conflicting results on safety and biocompatibility of nanomaterials, it is recognized that validation of analytical methods used to determine toxicity is necessary. Since engineered nanomaterials are so unique and complex, standardizing analytical methods for nanoparticle characterization is rather complicated. As reviewed by Hall et al., complete evaluation of nanoparticles for therapeutic use include thorough physicochemical property characterization, sterility and pyrogenicity assessment, biodistribution, and toxicity determination (both in vitro and in vivo) [124].

Powers et al. recognized that material properties are complicated by the behavior of the material in biological environments and that traditional methods of characterizing powder forms of nanomaterials may be ineffective for characterizing materials in biological systems. They proposed key characteristics that should be evaluated and reviewed analytical methods of measuring nanomaterial size and shape, dispersion, physicochemical properties, surface area, porosity, and surface [14]. In particular, it was suggested that transmission electron microscopy (TEM) and dynamic light scattering (DLS) would be suitable techniques for size and shape measurements in biological systems $[14,124]$. TEM and DLS was successfully applied to a study by Murdock et al. to characterize aggregation of various nanomaterials in water and culture media (with and without serum) [125].

In vivo distribution and toxicity examinations should include studies such as initial disposition, therapeutic efficacy, and dose-response studies, at a minimum. Distribution studies have been conducted where nanomaterials were tracked in the blood and tissues by conjugating the material with a radiolabel or organic dye, if direct detection of the material was not achievable. Degradation of the conjugate and the inevitable radiolabel decay or dye quenching limit this technique for toxicity studies where long-term evaluations are necessary. If possible, detection based on the material intrinsic properties is preferred, especially if the material is stable, to avoid misleading results [69]. However, since metabolism and degradation is often observed with nanomaterials used in vivo, detection strategies for analysis of all major parts of the nanomaterial, although challenging, would be the most ideal approach (i.e. a multi-indicator approach) $[6,124]$. Currently, toxicity assessments are performed by probing for inflammation. Tissue histological examination for immune response is traditionally performed, with some studies of overall animal behavior and weight loss as indicators of material intolerance. Moreover, analysis of biomarkers of inflammation, cell viability, and oxidative stress generation would enhance mechanistic studies into nanomaterial toxicity [65]. A summary of the conducted toxicity in vivo toxicity studies of the four presented nanomaterials is displayed in Table 2.

\section{Summary, conclusions and future challenges}

Although studies are conflicting regarding the magnitude and mechanisms of nanomaterial toxicity, it is evident that some nanomaterials that were previously considered biocompatible due to safety of the bulk material may indeed be toxic. Nanomaterial size, shape, surface chemistry, and degree of aggregation influence the production of free radicals and subsequent oxidative stress. Nanoparticle toxicology is a relatively young field, and the bulk of reports have focused on acute toxicity. Long-term toxicity of the materials and examination of chronic exposure are critical to understanding the toxicology of nanomaterials in vivo. Evaluation of toxicity has proven to be challenging as several factors may be working in tandem to cause nanoparticle toxicity. Furthermore, as nanomaterials are inherently quite complex, many unexpected interactions (based on bulk properties) with biological components may arise. 
However, with appropriately validated analytical methods and carefully designed experimentation, the mechanisms of toxicity may become clearer so that nanomaterials can safely be used as therapeutics and as diagnostic tools.

\section{Acknowledgements}

MLF would like to acknowledge support from the National Institutes of Health (R21 CA132033 and P20 RR015563), the American Cancer Society (RSG-08-133-01-CDD), the American Association of Colleges of Pharmacy, and the Kansas Masonic Cancer Center. CB would like to acknowledge support from the American Heart Association, the NIH (R03 AR054035, P20 RR016443), the Department of Defense, the NSF (CHE 0719464), the Coulter Foundation, the Higuchi Biosciences Center, and the Cystic Fibrosis Foundation.

\section{References}

1. De Jong WH, Borm PJA. Drug delivery and nanoparticles: applications and hazards. Int. J. Nanomedicine 2008;3:133-149. [PubMed: 18686775]

2. Garnett MC, Kallinteri P. Nanomedicines and nanotoxicity: some physiological principles. Occup. Med 2006;56:307-311.

3. Lanone S, Boczkowski J. Biomedical applications and potential health risks of nanomaterials: molecular mechanisms. Curr. Mol. Med 2006;6:651-663. [PubMed: 17022735]

4. Nel A, Xia T, Mädler L, Li N. Toxic potential of materials at the nanolevel. Science 2006;311:622627. [PubMed: 16456071]

5. Dobrovolskaia MA, McNeil SE. Immunological properties of engineered nanomaterials. Nat. Nanotechnol 2007;2:469-478. [PubMed: 18654343]

6. Fischer HC, Chan WCW. Nanotoxicity: the growing need for in vivo study. Curr. Opin. Biotechnol 2007;18:565-571. [PubMed: 18160274]

7. Kreyling WG, Semmler-Behnke M, Möller W. Health implications of nanoparticles. J. Nanopart. Res 2006;8:543-562.

8. Oberdörster G, Oberdörster E, Oberdörster J. Nanotoxicology: an emerging discipline evolving from studies of ultrafine particles. Environ. Health Perspect 2006;113:823-839.

9. Papp T, Schiffmann D, Weiss D, Castranova V, Vallyathan V, Rahman Q. Human health implications of nanomaterial exposure. Nanotoxicology 2008;2:9-27.

10. Powers KW, Brown SC, Krishna VB, Wasdo SC, Moudgil BM, Roberts SM. Research strategies for safety evaluation of nanomaterials. part VI. characterization of nanoscale particles for toxicological evaluation. Toxicol. Sci 2006;90:296-303. [PubMed: 16407094]

11. Rahman I. Regulation of nuclear factor- $\kappa \mathrm{B}$, activator protein-1, and glutathione levels by tumor necrosis factor- $\alpha$ and dexamethasone in alveolar epithelial cells. Biochem. Pharmacol 2000;60:10411049. [PubMed: 11007940]

12. Rahman I, Biswas SK, Jimenez LA, Torres M, Forman HJ. Glutathione, stress responses, and redox signaling in lung inflammation. Antioxid. Redox Signaling 2005;7:42-59.

13. Unfried K, Albrecht C, Klotz L-O, Von Mikecz A, Grether-Beck S, Schins RPF. Cellular response to nanoparticles: target structures and mechanisms. Nanotoxicology 2007;1:52-71.

14. Powers KW, Palazuelos M, Moudgil BM, Roberts SM. Characterization of the size, shape, and state of dispersion of nanoparticles for toxicological studies. Nanotoxicology 2007;1:42-51.

15. Rejman J, Oberle V, Zuhorn IS, Hoekstra D. Size-dependent internalization of particles via the pathways of clarthrin- and caveolae-mediated endocytosis. Biochem. J 2004;377:159-169. [PubMed: 14505488]

16. Elder A, Yang H, Gwiazda R, Teng X, Thurston S, He H, Oberdörster G. Testing nanomaterials of unknown toxicity: an example based on platinum nanoparticles of different shapes. Adv. Mater 2007;19:3124-3129.

17. Liu A, Sun K, Yang J, Zhao D. Toxicological effects of mult-wall carbon nanotubes in rats. J. Nanopart. Res 2008;10:1303-1307. 
18. Zhu M-T, Feng W-Y, Wang B, Wang T-C, Gu Y-Q, Wang M, Wang Y, Ouyang H, Zhao Y-L, Chai Z-F. Comparative study of pulmonary responses to nano- and submicron-sized ferric oxide in rats. Toxicology 2008;247:102-111. [PubMed: 18394769]

19. Champion JA, Smitragotri S. Role of target geometry in phagocytosis. Proc. Natl. Acad. Sci. U.S.A 2008;103:4930-4934. [PubMed: 16549762]

20. Duncan R. The dawning era of polymer therapeutics. Nat. Rev. Drug Discov 2003;2:347-360. [PubMed: 12750738]

21. Duncan R, Izzo L. Dendrimer biocompatibility and toxicity. Adv. Drug Deliv. Rev 2005;57:22152237. [PubMed: 16297497]

22. Cai CZ, Chen ZY. Intrinsic viscosity of starburst dendrimers. Macromolecules 1998;31:6393-6396.

23. Malik N, Wiwattanapatapee R, Klopsch R, Lorenz K, Frey H, Weener JW, Meijer EW, Paulus W, Duncan R. Dendrimers: Relationship between structure and biocompatibility in vitro, and preliminary studies on the biodistribution of I-125-labelled polyamidoamine dendrimers in vivo. J. Control. Release 2000;65:133-148. [PubMed: 10699277]

24. Roberts JC, Bhalgat MK, Zera RT. Preliminary biological evaluation of polyamidoamine (PAMAM) Starburst(TM) dendrimers. J. Biomed. Mater. Res. A 1996;30:53-65.

25. Agashe HB, Dutta T, Garg M, Jain NK. Investigations on the toxicological profile of functionalized fifth-generation poly(propylene imine) dendrimer. J. Pharm. Pharmacol 2006;58:1491-1498.

[PubMed: 17132212]

26. Pistolis G, Malliaris A, Tsiourvas D, Paleos CM. Poly(propyleneimine) dendrimers as $\mathrm{pH}$-sensitive controlled-release systems. Chem.-Eur. J 1999;5:1440-1444.

27. Lim J, Guo Y, Rostollan CL, Stanfield J, Hsieh JT, Sun XK, Simanek EE. The role of the size and number of polyethylene glycol chains in the biodistribution and tumor location of triazine dendrimers. Mol. Pharm 2008;5:540-547. [PubMed: 18672950]

28. Zhang W, Jiang J, Qin CH, Perez LM, Parrish AR, Safe SH, Simanek EE. Triazine dendrimers for drug delivery: evaluation of solubilization properties, activity in cell culture, and in vivo toxicity of a candidate vehicle. Supramol. Chem 2003;15:607-616.

29. Boyd BJ, Kaminskas LM, Karellas P, Krippner G, Lessene R, Porter CJH. Cationic poly-L-lysine dendrimers: pharmacokinetics, biodistribution, and evidence for metabolism and bioresorption after intravenous administration to rats. Mol. Pharm 2006;3:614-627. [PubMed: 17009860]

30. Kaminskas LM, Boyd BJ, Karellas P, Henderson SA, Giannis MP, Krippner GY, Porter CJH. Impact of surface derivatization of poly-L-lysine dendrimers with anionic aryisulfonate or succinate groups on intravenous pharmacokinetics and disposition. Mol. Pharm 2007;4:949-961. [PubMed: 17953445]

31. Kaminskas LM, Boyd BJ, Karellas P, Krippner GY, Lessene R, Kelly B, Porter CJH. The impact of molecular weight and PEG chain length on the systemic pharmacokinetics of PEGylated poly Llysine dendrimers. Mol. Pharm 2008;5:449-463. [PubMed: 18393438]

32. Marx V. Poised to branch out. Nat. Biotechnol 2008;26:729-732. [PubMed: 18612287]

33. Rittner K, Benavente A, Bompard-Sorlet A, Heitz F, Divita G, Brasseur R, Jacobs E. New basic membrane-destabilizing peptides for plasmid-based gene delivery in vitro and in vivo. Mol. Ther 2002;5:104-114. [PubMed: 11829517]

34. Hong SP, Bielinska AU, Mecke A, Keszler B, Beals JL, Shi XY, Balogh L, Orr BG, Baker JR, Holl MMB. Interaction of poly(amidoamine) dendrimers with supported lipid bilayers and cells: Hole formation and the relation to transport. Bioconjug. Chem 2004;15:774-782. [PubMed: 15264864]

35. Stasko NA, Johnson CB, Schoenfisch MH, Johnson TA, Holmuhamedov EL. Cytotoxicity of polypropylenimine dendrimer conjugates on cultured endothelial cells. Biomacromolecules 2007;8:3853-3859. [PubMed: 18004811]

36. Heiden TCK, Dengler E, Kao WJ, Heideman W, Peterson RE. Developmental toxicity of low generation PAMAM dendrimers in zebrafish. Toxicol. Appl. Pharmacol 2007;225:70-79. [PubMed: 17764713]

37. Malik N, Evagorou EG, Duncan R. Dendrimer-platinate: a novel approach to cancer chemotherapy. Anti-Cancer Drugs 1999;10:767-776. [PubMed: 10573209] 
38. Plank C, Mechtler K, Szoka FC, Wagner E. Activation of the complement system by synthetic DNA complexes: A potential barrier for intravenous gene delivery. Hum. Gene Ther 1996;7:1437-1446. [PubMed: 8844203]

39. Wilbur DS, Pathare PM, Hamlin DK, Buhler KR, Vessella RL. Biotin reagents for antibody pretargeting. 3. Synthesis, radioiodination, and evaluation of biotinylated starburst dendrimers. Bioconjug. Chem 1998;9:813-825. [PubMed: 9815176]

40. De Jesus OLP, Ihre HR, Gagne L, Frechet JMJ, Szoka FC. Polyester dendritic systems for drug delivery applications: In vitro and in vivo evaluation, Bioconjug. Chem 2002;13:453-461.

41. Neerman MF, Zhang W, Parrish AR, Simanek EE. In vitro and in vivo evaluation of a melamine dendrimer as a vehicle for drug delivery. Int. J. Pharm 2004;281:129-132. [PubMed: 15288350]

42. El-Sayed M, Ginski M, Rhodes C, Ghandehari H. Transepithelial transport of poly(amidoamine) dendrimers across Caco-2 cell monolayers. J. Control. Release 2002;81:355-365. [PubMed: 12044574]

43. Jevprasesphant R, Penny J, Jalal R, Attwood D, McKeown NB, D'Emanuele A. The influence of surface modification on the cytotoxicity of PAMAM dendrimers. Int. J. Pharm 2003;252:263-266. [PubMed: 12550802]

44. Bhadra D, Bhadra S, Jain S, Jain NK. A PEGylated dendritic nanoparticulate carrier of fluorouracil. Int. J. Pharm 2003;257:111-124. [PubMed: 12711167]

45. Chen HT, Neerman MF, Parrish AR, Simanek EE. Cytotoxicity, hemolysis, and acute in vivo toxicity of dendrimers based on melamine, candidate vehicles for drug delivery. J. Am. Chem. Soc 2004;126:10044-10048. [PubMed: 15303879]

46. Kobayashi H, Brechbiel MW. Nano-sized MRI contrast agents with dendrimer cores. Adv. Drug Deliv. Rev 2005;57:2271-2286. [PubMed: 16290152]

47. Kobayashi H, Kawamoto S, Saga T, Sato N, Hiraga A, Ishimori T, Akita Y, Brechbiel MW. MicroMR angiography of normal and intratumoral vessels in mice using dedicated intravascularMR contrast agents with high generation of polyamidoamine dendrimer core: reference to pharmacokinetic properties of dendrimer-based MR contrast agents. J. Magn. Reson. Imaging 2001;14:705-713. [PubMed: 11747027]

48. Kobayashi H, Sato N, Hiraga A, Saga T, Nakamoto Y, Ueda H, Konishi J, Togashi K, Brechbiel MW. 3D-micro-MR angiography of mice using macromolecular MR contrast agents with polyamidoamine dendrimer core with reference to their pharmacokinetic properties. Magn. Reson. Med 2001;45:454460. [PubMed: 11241704]

49. Sato N, Kobayashi H, Hiraga A, Saga T, Togashi K, Konishi J, Brechbiel MW. Pharmacokinetics and enhancement patterns of macromolecular MR contrast agents with various sizes of polyamidoamine dendrimer cores. Magn. Reson. Med 2001;46:1169-1173. [PubMed: 11746584]

50. Kobayashi H, Kawamoto S, Saga T, Sato N, Hiraga A, Ishimori T, Akita Y, Mamede MH, Konishi J, Togashi K, Brechbiel MW. Novel liver macromolecular MR contrast agents with a polypropyleneimine diaminobutyl dendrimer core: comparison to the vascular MR contrast agent with the polyamidoamine dendrimer core. Magn. Reson. Med 2001;46:795-802. [PubMed: 11590657]

51. Al-Jamal KT, Ruenraroengsak P, Hartell N, Florence AT. An intrinsically fluorescent dendrimer as a nanoprobe of cell transport. J. Drug Target 2006;14:405-412. [PubMed: 17092840]

52. Tam JP, Lu YA, Yang JL. Antimicrobial dendrimeric peptides. Eur. J. Biochem 2002;269:923-932. [PubMed: 11846794]

53. Luo D, Li Y, Um SH, Cu Y. A dendrimer-like DNA-based vector for DNA delivery; a viral and nonviral hybrid approach. Methods Mol. Med 2006;127:115-125. [PubMed: 16988451]

54. Ihre HR, De Jesus OLP, Szoka FC, Frechet JMJ. Polyester dendritic systems for drug delivery applications: Design, synthesis, and characterization. Bioconjug. Chem 2002;13:443-452. [PubMed: 12009932]

55. Liu MJ, Kono K, Frechet JMJ. Water-solube dendrimer-poly(ethylene glycol) starlike conjugates as potential drug carriers. J. Polym. Sci 1999;37:3492-3503.A1

56. Gillies ER, Dy E, Frechet JMJ, Szoka FC. Biological evaluation of polyester dendrimer: poly(ethylene oxide) "bow-tie" hybrids with tunable molecular weight and architecture. Mol. Pharm 2005;2:129_ 138. [PubMed: 15804187] 
57. Jorio A, Saito r. Hafner JH, Lieber CM, Hunter M, McClure T, Dresselhaus G, Dresselhaus MS. Structural $(n, m)$ determiniation of isolated single-walled carbon nanotubes by resonant raman scattering. Phys. Rev. Lett 2000;86:1118-1121. [PubMed: 11178024]

58. Lacerda L, Bianco A, Prato M, Kosterlos K. Carbon nanotubes as nanomedicines; from toxicology to pharmacology. Adv. Drug Deliv. Rev 2006;58:1460-1470. [PubMed: 17113677]

59. Kam NWS, O'Connell M, Wisdom JA, Dai H. Carbon nanotubes as multifunctional biological transporters and near-infrared agents for selective cancer cell destruction. Proc. Natl. Acad. Sci. U.S.A 2005;102:11600-11605. [PubMed: 16087878]

60. Fiorito S, Serafino A, Andreola F, Togna A, Togna G. Toxicity and biocompatibility of carbon nanoparticles. J. Nanosci. Nanotechnol 2006;6:591-599. [PubMed: 16573109]

61. Poland CA, Duffin R, Kinloch I, Maynard A, Wallace WA, Seaton A, Stone V, Brown S, Macnee W, Donaldson K. Carbon nanotubes introduced into the abdominal cavity of mice show asbestoslike pathogenicity in a pilot study. Nat. Nanotechnol 2008;3:423-428. [PubMed: 18654567]

62. Takagi A, Hirose A, Nishimura T, Fukumori N, Ogata A, Ohashi N, Kitajima S, Kanno J. Induction of mesothelioma in $\mathrm{p} 53+/-$ mouse by intraperitoneal application of mult-wall carbon nanotube. J. Toxicol. Sci 2008;33:105-116. [PubMed: 18303189]

63. Cherukuri P, Gannon CJ, Leeuw TK, Schmidt HK, Smalley RE, Curley SA, Weisman RB. Mammalian pharmacokinetics of carbon nanotubes using intrinsic near-infrared fluorescence. Proc. Natl. Acad. Sci. U.S.A 2006;103:18882-18886. [PubMed: 17135351]

64. Yang S, Wang X, Jia G, Gu Y, Wang T, Nie H, Ge C, Wang H, Liu Y. Long-term accumulation and low toxicity of single-walled carbon nanotubes in intravenously exposed mice. Toxicol. Lett 2008;181:182-189. [PubMed: 18760340]

65. Yang S, Guo W, Lin Y, Deng X, W. H. Sun H, Liu Y, Wang X, Wang W, Chen M, Huang Y, Sun Y. Biodistribution of pristine single-walled carbon nanotubes in vivo. J. Phys. Chem. C 2007;111:17761-17764.

66. Soto K, Garza KM, Murr LE. Cytotoxic effects of aggregated nanomaterials. Acta Biomater 2007;3:351-358. [PubMed: 17275430]

67. Wick P, Manser P, Limbach LK, Dettlaff-Wegilkowska U, Krumeich F, Roth S, Stark WJ, Bruinink A. The degree and kind of agglomeration affect carbon nanotube cytotoxicity. Toxicol. Lett 2007;168:121-131. [PubMed: 17169512]

68. Fraczek A, Menaszek E, Paluszkiewicz C, Blazewicz M. Comparative in vivo biocompatability study of single- and multi-wall carbon nanotubes. Acta Biomater 2008;4:1593-1602. [PubMed: 18585111]

69. Liu Z, Davis, Cai W, He L, Chen X, Dai H. Circulation and long-term fate of functionalized biocompatible single-walled carbon nanotubes in mice probed by Raman spectroscopy. Proc. Natl. Acad. Sci. U.S.A 2008;105:1410-1415. [PubMed: 18230737]

70. Wang H, Wang J, Deng X, Sun H, Shi Z, Gu Z, Liu Y, Zhao Y. Biodistribution of carbon singlewalled carbon nanotubes in mice. J. Nanosci. Nanotechnol 2004;4:1019-1024. [PubMed: 15656196]

71. Singh R, Pantarotto D, Lacerda L, Pastorin G, Klumpp C, Prato M, Bianco A, Kosterlos K. Tissue biodistribution and blood clearance rates of intravenously administered carbon nanotube radiotracers. Proc. Natl. Acad. Sci. U.S.A 2006;103:3357-3362. [PubMed: 16492781]

72. Hirano S, Kanno S, Furuyama A. Multi-walled carbon nanotubes injure the plasma membrane of macrophages. Toxicol. Appl. Pharmacol 2008;232:244-251. [PubMed: 18655803]

73. Donaldson K, Aitken R, Tran L, Stone V, Duffin R, Forrest G, Alexander A. Carbon nanotubes; a review of their properties in relation to pulmonary toxicology and workplace safety. Toxicol. Sci 2006;92:5-22. [PubMed: 16484287]

74. Bruchez M Jr. Moronne M, Gin P, Weiss S, Alivisatos AP. Semiconductor nanocrystals as fluorescent biological labels. Science 1998;281:2013-2016. [PubMed: 9748157]

75. Hardman R. A toxicologic review of quantum dots: toxicity depends on physicochemical and environmental factors. Environ. Health Perspect 2006;114:165-172. [PubMed: 16451849]

76. Chen Z, Chen H, Meng H, Xing G, Gao X, Sun B, Shi X, Yuan H, Zhang C, Liu R, Zhao F, Zhao Y, Fang X. Bio-distribution and metabolic paths of silica coated CdSeS quantum dots. Toxicol. Appl. Pharmacol 2008;230:364-371. [PubMed: 18495192]

77. Riegler J, Nann T. Application of luminescent nanocrystals as labels for biological molecules. Anal. Bioanal. Chem 2004;379:913-919. [PubMed: 15278340] 
78. Shiohara A, Hoshino A, Hanaki K, Suzuki K, Yamamoto K. On the cytotoxicity caused by quantum dots. Microbiol. Immunol 2004;48:669-675. [PubMed: 15383704]

79. Weng KC, Noble CO, Papahadjopoulos-Sternberg B, Chen FF, Drummond DC, Kirpotin DB, Wang D, Hom YK, Hann B, Park JW. Targeted tumor cell internalization and imaging of multifunctional quantum dot-conjugated immunoliposomes in vitro and in vivo. Nano Lett 2008;8:2851-2857. [PubMed: 18712930]

80. Cai W, Shin DW, Chen K, Gheysens O, Cao Q, Wang SX, Gambhir SS, Chen X. Peptide-labeled near-infrared quantum dots for imaging tumor vasculature in living subjects. Nano Lett 2006;6:669676. [PubMed: 16608262]

81. Colton HM, Falls JG, Ni H, Kwanyuen P, Creech D, McNeil E, Casey WM, Hamilton G, Cariello NF. Visualization and quantitation of peroxisomes using fluorescent nanocrystals: treatment of rats and monkeys with fibrates and detection in the liver. Toxicol. Sci 2004;80:183-192. [PubMed: 15084755]

82. Dubertret B, Skourides P, Norris DJ, Noireaux V, Brivanlou AH, Libchaber A. In vivo imaging of quantum dots encapsulated in phospholipid micelles. Science 2002;298:1759-1762. [PubMed: 12459582]

83. Gao X, Cui Y, Levenson RM, Chung LW, Nie S. In vivo cancer targeting and imaging with semiconductor quantum dots. Nat. Biotechnol 2004;22:969-976. [PubMed: 15258594]

84. Larson DR, Zipfel WR, Williams RM, Clark SW, Bruchez MP, Wise FW, Webb WW. Water-soluble quantum dots for multiphoton fluorescence imaging in vivo. Science 2003;300:1434-1436. [PubMed: 12775841]

85. Lidke DS, Nagy P, Heintzmann R, Arndt-Jovin DJ, Post JN, Grecco HE, Jares-Erijman EA, Jovin TM. Quantum dot ligands provide new insights into erbB/HER receptor-mediated signal transduction. Nat. Biotechnol 2004;22:198-203. [PubMed: 14704683]

86. Choi HS, Liu W, Misra P, Tanaka E, Zimmer JP, Itty Ipe B, Bawendi MG, Frangioni JV. Renal clearance of quantum dots. Nat. Biotechnol 2007;25:1165-1170. [PubMed: 17891134]

87. Dabbousi BO, Rodriguez-Viejo J, Mikulec FV, Heine JR, Mattoussi H, Ober R, Jensen KF, Bawendi M. (CdSe)ZnS core-shell quantum dots: synthesis and characterization of a size series of highly luminescent nanocrystallites. J. Phys. Chem. B 1997;101:9463-9475.

88. Kim S, Fisher B, Eisler HJ, Bawendi M. Type-II quantum dots: $\mathrm{CdTe} / \mathrm{CdSe}$ (core/shell) and CdSe/ ZnTe(core/shell) heterostructures. J. Am. Chem. Soc 2003;125:11466-11467. [PubMed: 13129327]

89. Yang RS, Chang LW, Wu JP, Tsai MH, Wang HJ, Kuo YC, Yeh TK, Yang CS, Lin P. Persistent tissue kinetics and redistribution of nanoparticles, quantum dot 705, in mice: ICP-MS quantitative assessment. Environ. Health Perspect 2007;115:1339-1343. [PubMed: 17805425]

90. Babier O, Jacquillet G, Tauc M, Cougnon M, Poujeol P. Effect of heavy metals on, and handling by, the kidney. Neprhon Physiol 2005;99:105-110.

91. Akgun H, Gonlusen G, Cartwright J Jr. Suki WN, Truong LD. Are gadolinium-based contrast media nephrotoxic? Arch. Pathol. Lab. Med 2006;130:1354-1357. [PubMed: 16948524]

92. Zhang T, Stilwell JL, Gerion D, Ding L, Elboudwarej O, Cooke PA, Gray JW, Alivisatos AP, Chen FF. Cellular effect of high doses of silica-coated quantum dot profiled with high throughput gene expression analysis and high content cellomics measurements. Nano Lett 2006;6:800-808. [PubMed: 16608287]

93. Hamilton SJ. Review of selenium toxicity in the aquatic food chain. Sci. Total Environ 2004;326:131. [PubMed: 15142762]

94. Henson MC, Chedrese PJ. Endocrine disruption by cadmium, a common environmental toxicant with paradoxical effects on reproduction. Exp. Biol. Med. (Maywood) 2004;229:383-392. [PubMed: 15096650]

95. Derfus AM, Chan CW, Bhatia SN. Probing the cytotoxicity of semiconductor quantum dots. Nano Lett 2004;4:11-18.

96. Mancini MC, Kairdolf BA, Smith AM, Nie S. Oxidative quenching and degradation of polymerencapsulated quantum dots: new insights into the long-term fate and toxicity of nanocrystals in vivo. J. Am. Chem. Soc 2008;130:10836-10837. [PubMed: 18652463]

97. Zhang YB, Chen W, Zhang J, Liu J, Chen GP, Pope C. In vitro and in vivo toxicity of CdTe nanoparticles. J. Nanosci. Nanotechnol 2007;7:497-503. [PubMed: 17450785] 
98. Geys J, Nemmar A, Verbeken E, Smolders E, Ratoi M, Hoylaerts MF, Nemery B, Hoet PHM. Acute Toxicity and Prothrombotic Effects of Quantum Dots:Impact of Surface Charge, Environ. Health Perspect 2008;116:1607-1613.

99. Hoshino A, Fujioka K, Oku T, Suga M, Sasaki YF, Ohta T, Yasuhara M, Suzuki K, Yamamoto K. Physiocochemical properties and cellular toxicity of nanocrystal quantum dots depend on their surface modification. Nano Lett 2004;4:2163-2169.

100. Hoshino A, Hanaki K, Suzuki K, Yamamoto K. Applications of T-lymphoma labeled with fluorescent quantum dots to cell tracing markers in mouse body. Biochem. Biophys. Res. Commun 2004;314:46-53. [PubMed: 14715244]

101. Ballou B, Lagerholm BC, Ernst LA, Bruchez MP, Waggoner AS. Noninvasive imaging of quantum dots in mice. Bioconjug. Chem 2004;15:79-86. [PubMed: 14733586]

102. Robe A, Pic E, Lassalle H, Bezdetnaya L, Guillemin F, Marchal F. Quantum dots in axillary lymph node mapping: biodistribution study in healthy mice. BMC Cancer 2008;22:111-1120. [PubMed: 18430208]

103. Gopee NV, Roberts DW, Webb P, Cozart CR, Siitonen PH, Warbritton AR, Yu WW, Colvin VL, Walker NJ, Howard PC. Migration of intradermally injected quantum dots to sentinel organs in mice. Toxicol. Sci 2007;98:249-257. [PubMed: 17404394]

104. Fischer HC, Liu L, Pang KS, Chan WCW. Pharmacokinetics of nanoscale quantum dots: in vivo distribution, sequestration, and clearance in the rat. Adv. Funct. Mater 2006;16:1299-1305.

105. De Jong WH, Hagens WI, Krystek P, Burger MC, Sips AJAM, Geertsma RE. Particle size-dependent organ distribution of gold nanoparticles after intravenous injection. Biomaterials 2008;29:19121919. [PubMed: 18242692]

106. Chen PC, Mwakwari SC, Oyelere AK. Gold nanoparticles: from nanomedicine to nanosensing. Nanotechnology 2008;1:45-66.

107. Murphey CJ, Gole A, Stone JW, Sisco PN, Alkany AM, Goldsmith EC, Baxter SC. Gold nanoparticles in biology: beyond toxicity to cellular imaging. Acc. Chem. Res 2008;41:1721-1730. [PubMed: 18712884]

108. Graham GG, Whitehouse MW, Bushell GR. Aurocyanide, dicyano-aurate (I), a pharmacologically active metabolite of medicinal gold complexes. Inflammopharmacology 2008;16:126-132. [PubMed: 18521543]

109. Williams ML. Core chemistry of gold and its complexes. Inflammopharmacology 2008;16:110111. [PubMed: 18521544]

110. Sopjani M, Föller M, Lang F. Gold stimulates $\mathrm{Ca}^{2+}$ entry into and subsequent suicidal death of erythrocytes. Toxicology 2008;244:271-279. [PubMed: 18207621]

111. Sereemaspun A, Rojanathanes R, Wiwanitkit V. Effect of gold nanoparticle on renal cell: an implication for exposure risk. Ren. Fail 2008;30:323-325. [PubMed: 18350452]

112. Schmid G. The relevance of shape and size of Au 55 clusters. Chem. Soc. Rev 2008;337:1909-1930. [PubMed: 18762839]

113. Tsoli M, Kuhn H, Brandau W, Esche H, Schmid G. Cellular uptake and toxicity of Au 55 clusters. Small 2005;1:841-844. [PubMed: 17193536]

114. Pan Y, Neuss S, Leifert A, Fischler M, Wen F, Simon U, Schmid G, Brandau W, Jahnen-Dechent W. Size-dependent cytotoxicity of gold nanoparticles. Small 2007;3:1941-1949. [PubMed: 17963284]

115. Chithrani BD, Ghazani AA, Chan WCW. Determining the size and shape dependence of gold nanoparticle uptake into mammalian cells. Nano Lett 2006;6:662-668. [PubMed: 16608261]

116. Chithrani BD, Chan WCW. Elucidating the mechanism of cellular uptake and removal of proteincoated gold nanoparticles of different sizes and shapes. Nano Lett 2007;7:1542-1550. [PubMed: 17465586]

117. Sonavane G, Tomoda K, Makino K. Biodistribution of colloidal gold nanoparticles after intravenous administration: effect of particle size, Colloids Surf. B Biointerfaces 2008;66:274-280.

118. Sandhu KK, McIntosh CM, Simard JM, Smith SW, Rotello VM. Gold nanoparticle-mediated transfection of mammalian cells. Bioconjug. Chem 2002;13:3-6. [PubMed: 11792172]

119. Goodman CM, McCusker CD, Yilmaz T, Rotello VM. Toxicity of gold nanoparticles functionalized with cationic and anionic side chains. Bioconjug. Chem 2004;15:897-900. [PubMed: 15264879] 
120. Wang S, Lu W, Tovmachenko O, Rai US, Yu H, Ray PC. Challenge in understanding size and shape dependent toxicity of gold nanomaterials in human skin keratinocytes. Chem. Phys. Lett 2008;463:145-149.

121. Connor EE, Mwamuka J, Gole A, Murphy CJ, Wyatt MD. Gold nanoparticles are taken up by human cells but do not cause acute cytotoxicity. Small 2005;1:325-327. [PubMed: 17193451]

122. Niidome T, Yamagata M, Okamoto Y, Akiyama Y, Takahashi H, Kawano T, Katayama Y, Niidome Y. PEG-modified gold nanorods with a stealth character in in vivo applications. J. Control. Release 2006;114:343-347. [PubMed: 16876898]

123. Huff TB, Hansen MN, Zhao Y, Cheng J, Wei A. Controlling the cellular uptake of gold nanoparticles. Langmuir 2007;23:1596-1599. [PubMed: 17279633]

124. Hall JB, Dobrovolskaia MA, Patri AK, McNeil SE. Characterization of nanoparticles for therapeutics. Nanomedicine 2007;2:789-803. [PubMed: 18095846]

125. Murdock RC, Braydich-Stolle L, Schrand AM, Schlager JJ, Hussain SM. Characterization of nanomaterial dispersion in solution prior to in vitro exposure using dynamic light scattering technique. Toxicol. Sci 2008;101:239-253. [PubMed: 17872897] 


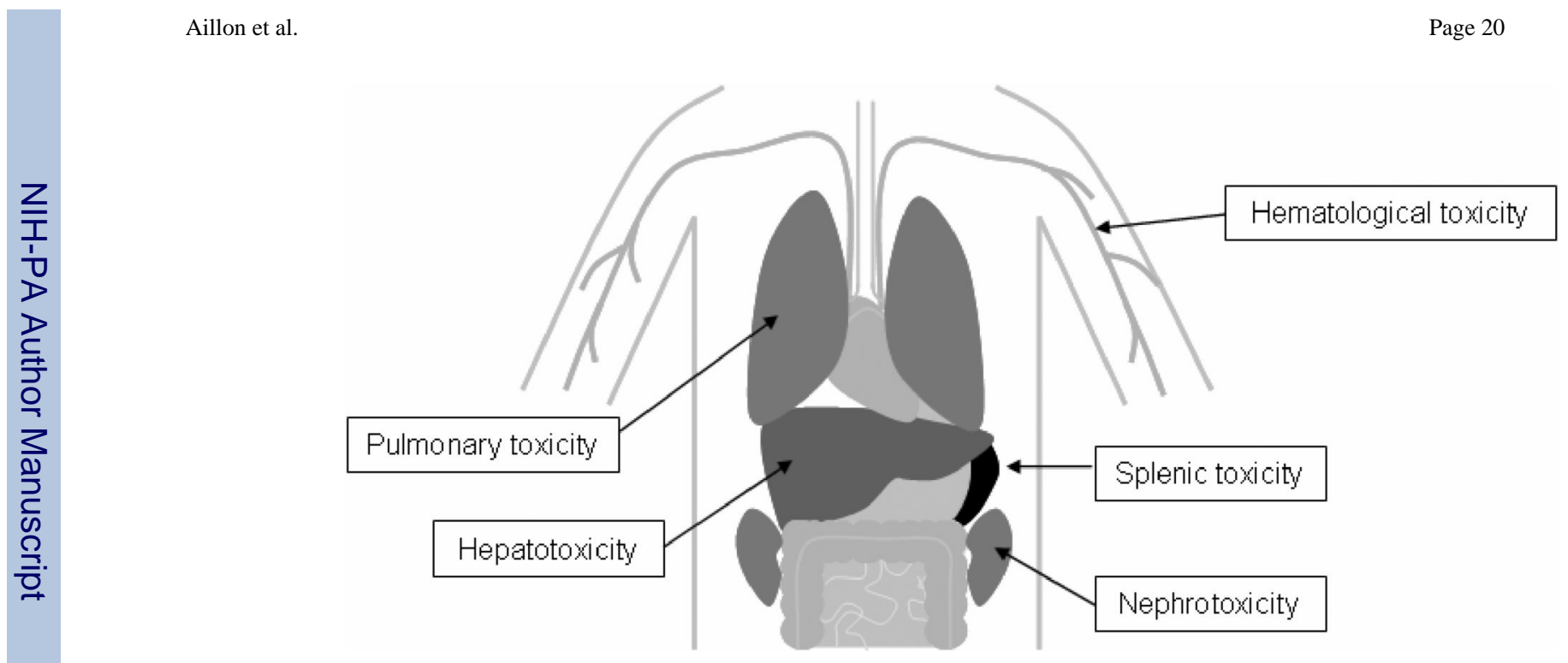

Figure 1.

Major forms of in vivo nanomaterial toxicity 
a)

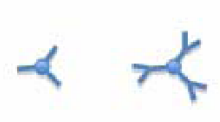

G1

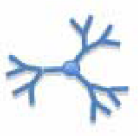

G3

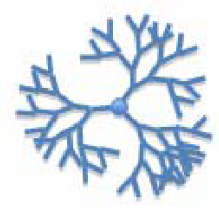

G5 b)

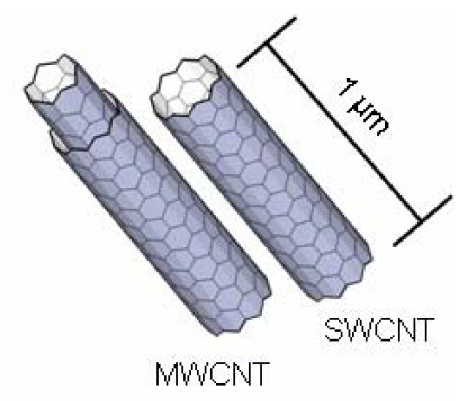

d)

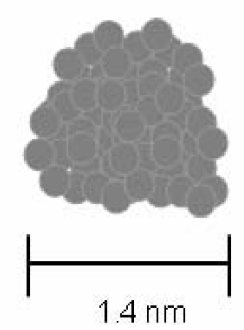

c)

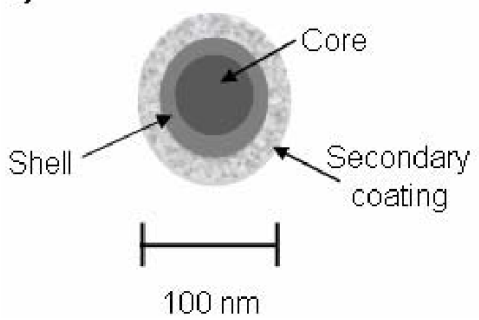

\section{Figure 2.}

Schematic of the structures of a) dendrimers of varying generations, b) carbon nanotubes, c) a quantum dot and d) a gold nanocluster 
Table 1

Summary of primary causes of nanomaterial toxicity in vivo

\begin{tabular}{lll}
\hline Nanomaterial Type & Primary Toxicity Concerns & Reference \\
\hline Dendrimers & Surface charge & {$[24][25][36][37]$} \\
& Size (generation) & {$[24]$} \\
Carbon nanotubes & Size (aggregation) & {$[63-68]$} \\
& Length & {$[61][62][72]$} \\
Quantum dots & Stability of core/shell/coating & {$[75][92][96]$} \\
& Type and surface charge of coating & {$[75][89][99-101][103][104]$} \\
Gold nanoparticles & Size & {$[105][112-117]$} \\
& Shape & {$[115][120-122]$} \\
\hline
\end{tabular}


Table 2

Summary of the conducted in vivo toxicity studies

\begin{tabular}{|c|c|c|c|c|}
\hline Nanomaterial & Toxicity Study & Analyzed Parameters & Study length & Reference \\
\hline \multirow[t]{5}{*}{ Dendrimers } & General toxicity & $\begin{array}{l}\text { Behavior, weight change, } \\
\text { mortality }\end{array}$ & $24 \mathrm{~h}-6$ months & $\begin{array}{l}{[24][37][40]} \\
{[45]}\end{array}$ \\
\hline & Hematological toxicity & Complete blood count & 7 days & [25] \\
\hline & Immunogenicity & $\begin{array}{l}\text { IP, ODD, Antibody (IgG) titre } \\
\text { by ELISA }\end{array}$ & 21-52 days & {$[24][25]$} \\
\hline & Hepatotoxicity & Histology, serum ALT & $48 \mathrm{~h}-6$ months & [24] [41] \\
\hline & Nephrotoxicity & BUN & $48 \mathrm{~h}-6$ weeks & {$[41]$} \\
\hline \multirow[t]{7}{*}{ Carbon nanotubes } & PK and distribution & Radiolabel & $24 \mathrm{~h}-18$ days & {$[70][71]$} \\
\hline & & TEM of tissues, urine $\&$ feces & 90 days & [64] [65] [61] \\
\hline & & Raman spectroscopy & 90 days & [64] [69] \\
\hline & & Near-infrared fluorescence & $24 \mathrm{~h}$ & [63] \\
\hline & Tissue inflammation & Histology & 7 - 90 days & [61] [64] [68] \\
\hline & Hepatic function & Serum LDH, TBIL, ALT, AST & 90 days & {$[64]$} \\
\hline & Oxidative stress & $\begin{array}{l}\text { Tissue glutathione \& MDA } \\
\text { levels }\end{array}$ & 90 days & {$[64]$} \\
\hline \multirow[t]{4}{*}{ Quantum dots } & PK and distribution & TEM of tissues & $90 \min -24 \mathrm{~h}$ & {$[101][104]$} \\
\hline & & Weight change & 28 days & [89] \\
\hline & & ICP-MS of tissue homogenates & $3 \mathrm{hrs}-28$ days & [89] [104] \\
\hline & & Fluorescence spectroscopy & 28 days & [89] \\
\hline Gold nanoparticles & PK and distribution & ICP-MS of tissue homogenates & $24 \mathrm{~h}$ & {$[105][117]$} \\
\hline
\end{tabular}

*IP = Immunoprecipitation; ODD = Ouchterlony double diffusion; ALT = alanine aminotransferase; BUN = blood urea nitrogen; LDH = lactose dehydrogenase; $\mathrm{TBIL}=$ total bilirubin $; \mathrm{AST}=$ aspartate aminotransferase; $\mathrm{MDA}=$ malondialdehyde 